\title{
Role of ghrelin in reproduction
}

\author{
María C García, Miguel López, Clara V Alvarez, Felipe Casanueva ${ }^{1}$, Manuel Tena-Sempere ${ }^{2}$ \\ and Carlos Diéguez
}

Department of Physiology, School of Medicine, University of Santiago de Compostela, R/San Francisco s/n, 15782 Santiago de Compostela (A Coruña), Spain, ${ }^{1}$ Endocrine Section, Department of Medicine, Complejo Hospitalario Universitario de Santiago de Compostela, University of Santiago de Compostela, Santiago de Compostela, Spain and ${ }^{2}$ Physiology Section, Department of Cell Biology, Physiology and Immunology, Faculty of Medicine, University of Cordoba, Avda. Menendez Pidal s/n, 14004 Cordoba, Spain

Correspondence should be addressed to C Diéguez; Email: fscadigo@usc.es

\begin{abstract}
Ghrelin, the endogenous ligand of GH secretagogue receptor type 1a, has emerged as a pleiotropic modulator of diverse biological functions, including energy homeostasis and, lately reproduction. Here, we review recent reports evaluating the reproductive effects and sites of action of ghrelin, with particular emphasis regarding its role as a molecule integrating reproductive function and energy status. Data gleaned from rodent studies clearly show that besides having direct gonadal effects, ghrelin may participate in the regulation of gonadotropin secretion and it may influence the timing of puberty. In addition, experimental data showing that ghrelin and/or its receptor are expressed in normal human ovary and testis as well as in human ovarian and testicular tumors raise the possibility that the ghrelin system may be involved in the control of cell proliferation in these tumors. We propose that ghrelin either acting as an endocrine and/or paracrine signal may play a major role in the endocrine network that integrates energy balance and reproduction.

Reproduction (2007) 133 531-540
\end{abstract}

\section{Introduction: historical remarks}

Major attention on ghrelin started in December 1999, when the endogenous ligand for the growth hormone secretagogue receptor (GHS-R) type 1a was reported (Kojima et al. 1999). The ligand was named ghrelin from the Proto-Indo-European word of 'ghre', which means grow, and 'relin' as it had GH-releasing activities. Ghrelin is a 28 amino acid peptide with a fatty acid chain modification on the $\mathrm{N}$-terminal third amino acid. Interestingly, at the same time, a stomach-derived mRNA sequence was identified as coding for a protein with sequence similarities to motilin and named motilinrelated peptide m46 (Tomasetto et al. 2000). Structural analysis, aimed at identifying the amino acid sequence of ghrelin, identified a discrepancy between the observed and calculated molecular weight and pointed to the presence of a post-translational modification. Indeed, the hydroxyl group of the third $\mathrm{N}$-terminal amino acid serine residue was found to be esterified by an n-octanoic acid (Kojima et al. 1999). No other naturally occurring peptide has been previously shown to have this acyl group as a post-translational modification. A spliced variant of ghrelin with 27 amino acids, missing the 14th amino acid (glutamine), was also identified. Later, biologically active analogues of ghrelin were described in much smaller amounts with acyl chains of 10 or $11 \mathrm{C}$ atoms or carbon unsaturations (Hosoda et al. $2000 b$ ). The $n$-octanoyl group at the $\mathrm{Ser}^{3}$ of the ghrelin molecule seems to be essential for some of the hormone's bioactivity, including $\mathrm{GH}$ release and orexigenic effect. Unacylated (desoctanoyl or desacyl) ghrelin circulates in far greater concentrations than the acylated form and does not displace ghrelin from its hypothalamic and pituitary binding sites (Hosoda et al. 2000a) and is unable to stimulate $\mathrm{GH}$ release in vivo in rats and humans (Kojima et al. 1999, Broglio et al. 2003). Although in the beginning it was widely accepted that unacylated ghrelin (UAG) was devoid of any biological activity, increasing numbers of studies report different biological effects of UAG, which is now considered as a peptide with specific and wide ranging actions in different tissues (Cassoni et al. 2001, Bedendi et al. 2003, Nanzer et al. 2004, Thompson et al. 2004).

This review will more closely address the role of ghrelin in human and rodent reproduction, rather than its role as metabolic hormone, by focusing on its endocrine 
and/or paracrine effects in the regulation of the hypothamic-pituitary-gonadal axis.

\section{Ghrelin system in the testis}

One of the reproductive tissues where expression and/or function of ghrelin were first evaluated was the testis. The possibility of direct gonadal actions of ghrelin was conceivable given the documented effects of other peripheral regulators of energy balance, such as leptin, in the male gonad (Tena-Sempere \& Barreiro 2002). Indeed, in the last three years, a wealth of evidence has been gathered suggesting that ghrelin and its functional receptor, the GHS-R1a, are expressed in mammalian testis, where ghrelin might conduct specific regulatory actions.

\section{Rodent data}

The initial evidence for testicular expression of the ghrelin gene came from a study by Tanaka et al. (2001), who identified a testis-specific ghrelin gene derived transcript in the mouse. This ghrelin transcript was composed of a distinct 68-bp sequence at the $5^{\prime}$-end, followed by a 252-bp sequence corresponding to exons 4 and 5 of the mouse ghrelin gene (Tanaka et al. 2001). Notably, expression of 'full-length' ghrelin mRNA in the mouse testis was not detected in that study, using Northern hybridization.

In parallel, our research group initiated the analysis of the pattern of expression of ghrelin and its cognate receptor (GHS-R1a) in the rat testis, by a combination of molecular and immunological approaches. Thus, testicular ghrelin gene expression was demonstrated by semiquantitative RT-PCR throughout postnataldevelopment, and ghrelin peptide was selectively detected in rat Leydig cells at advanced stages of maturation, regardless of their fetal or adult origin (Barreiro et al. 2002, Tena-Sempere et al. 2002). Accordingly, ghrelin expression became undetectable after selective elimination of mature Leydig cells by administration of the cytotoxic compound ethylene dimethane sulfonate (EDS; Barreiro et al. 2002, Tena-Sempere et al. 2002). Analyses of its regulation by hormonal signals revealed that ghrelin expression in the testis is not apparently modulated by follicle-stimulating hormone (FSH), GH, thyroid hormones and glucocorticoids, but it is, at least partially, under the control of pituitary luteinizing hormone ( $\mathrm{LH}$; Barreiro et al. 2002). This is in good agreement with the fact that testicular LH/CG receptors are solely expressed in Leydig cells (Tena-Sempere \& Huhtaniemi 2003).

In addition to the ligand, expression of the putative ghrelin receptor was demonstrated by a combination of semiquantitative RT-PCR and in situ hibrization in rat testis (Tena-Sempere et al. 2002, Barreiro et al. 2003).
Notably, net testicular expression of GHS-R gene was detected at rather constant relative levels throughout postnatal development in the rat. In contrast, isoformspecific GHS-R1a mRNA was undetectable at prepubertal stages whereas it sharply increased thereafter, with peak values in adulthood (Barreiro et al. 2003). This observation suggests that during pubertal development a shift in the pattern of splicing of the GHS-R gene takes place in rat testis that favours expression of the biologically active type $1 \mathrm{a}$ form of the receptor, which might imply considerable changes in net ghrelin sensitivity with sexual maturation. Location analyses in the rat testis by means of immunohistochemistry and in situ hybridization revealed a scattered pattern of distribution of GHS-R1a, with specific expression in somatic Sertoli and Leydig cells, and eventually in germ cells (Barreiro et al. 2003). As was demonstrated for the ligand, testicular expression of GHS-R gene appeared under hormonal regulation: GHS-R1a mRNA levels were stimulated, within a range of doses, by ghrelin and pituitary FSH. Thus, not only ghrelin expression, but also testicular sensitivity to ghrelin is likely regulated by hormonal (homologous and heterologous) signals, which is highly suggestive of a finely tuned, direct action of ghrelin in the control of testicular function.

Besides expression analyses, direct biological actions of ghrelin in the rat testis have been demonstrated in our laboratory using a combination of in vivo and in vitro approaches. First, ghrelin was proven to significantly inhibit, in a dose-dependent manner, stimulated testosterone secretion. The inhibitory effect of ghrelin upon testosterone secretion was associated with a significant decrease in human choriogonadotropin (hCG)-stimulated levels of the mRNAs encoding several key factors in the steroidogenic route, such as steroid acute regulatory protein, and the enzymes P450 side-chain cleavage, $3 \beta$ hydroxyl steroid dehydrogenase (HSD) and testisspecific $17 \beta$-HSD type III. The fact that ghrelin equally decreased hCG- and CAMP-induced testosterone secretion indicates that this inhibitory action must take place in a step beyond cAMP formation (Tena-Sempere et al. 2002). Considering that the major stimulant for testicular expression of ghrelin is pituitary $\mathrm{LH}$, it is tempting to speculate that ghrelin might operate as a local regulator in the fine-tuning of the steroidogenic actions of $\mathrm{LH}$, which might participate in the autolimitation of testicular testosterone response to gonadotropic stimulation (Barreiro et al. 2002). Alternatively, such an inhibitory effect upon testosterone secretion might be conducted by the systemic, gut-derived ghrelin, whose plasma levels are inversely correlated with body mass index (Dornonville et al. 2005). Thereby, elevated ghrelin levels (as those observed in energy insufficiency) might contribute to the suppression of male reproductive axis in situations of negative energy balance, such as starvation. 
In addition to its steroidogenic effects, ghrelin might also directly regulate seminiferous tubule functions, as expression of GHS-R1a was demonstrated in the tubular compartment of the testis (Barreiro et al. 2003). Indeed, we have recently demonstrated the ability of ghrelin to inhibit expression of the gene encoding stem cell factor (SCF), both after intratesticular injection in vivo as well as following challenge of staged seminiferous tubule fragments in culture (Barreiro et al. 2004). Notably, SCF is a Sertoli cell product that has been identified as the major paracrine stimulator of germ cell development, acting as a survival factor for spermatogonia, spermatocytes and spermatids in the adult rat seminiferous epithelium (Hakovirta et al. 1999, Yan et al. 2000b). In addition, testicular SCF has been involved also in Leydig cell development and survival (Yan et al. 2000a). Thus, the actions of ghrelin upon tubular SCF mRNA expression may have implications not only in the control of spermatogenesis but also upon Leydig cell proliferation. In fact, using in vivo models of intratesticular injection, we have recently demonstrated that ghrelin is able to inhibit the proliferative rate of immature Leydig cells both during puberty development and after selective ablation of pre-existing mature Leydig cells by administration of EDS (Barreiro et al. 2004). These observations highlight the potential complexity of ghrelin actions in the testis, where this peptide might operate as novel regulator of Leydig cell development. Moreover, besides its impact on testicular function, our current data open up the possibility that ghrelin may regulate additional biological systems through modulation of SCF gene expression.

\section{Human data}

Although most data on the expression and biological actions of ghrelin in the male gonad has been obtained in the rat, fragmentary evidence indicates that ghrelin and its functional receptor are also expressed in the human testis. In fact, initial screening analyses of ghrelin mRNA expression in human tissues provided evidence of expression of ghrelin gene in the testis (Gnanapavan et al. 2002); a finding that was confirmed by our group (Gaytan et al. 2004). Thereafter, the pattern of testicular expression of ghrelin in the human was further characterized. Immunohistochemical analyses detected that, as is the case in the rat, ghrelin peptide is strongly expressed in interstitial mature Leydig cells. However, a specific feature of testicular expression of ghrelin in the human is the presence of this peptide, albeit at low levels, also in Sertoli cells (Barreiro et al. 2003).

Besides the ligand, GHS-R1a expression in the human testis was also detected by means of molecular and immunohistochemical techniques. Thus, the presence of GHS-R1a was demonstrated, at the mRNA and peptide levels, in human testis tissue (Gaytan et al. 2004). This is in good agreement with previous data showing the presence of GHS binding sites in human gonads (Papotti et al. 2000). As was the case in the rat, testicular expression of GHS-R1a in the human showed a scattered pattern of distribution, with specific immunostaining being detected in somatic Sertoli and Leydig cells, as well as in germ cells, mainly in pachytene spermatocytes (Gaytan et al. 2004).

\section{Ghrelin system in the ovary \\ Rodent data}

Data gleaned recently have conclusively shown the expression of ghrelin (at the mRNA and peptide levels) in the adult rat ovary. To ascertain the physiological regulation of the ghrelin gene expression in the rat ovary, assessment of relative mRNA levels of this message was conducted through the different stages of the estrous cycle (Caminos et al. 2003). Interestingly, despite persistent expression of the signal at all stages tested, ghrelin mRNA levels significantly varied depending on the phase of the cycle, with the lowest expression levels in proestrus and maximum values in the diestrous (day 1 ) phase. Such a cyclic profile of expression, with peak levels in the luteal stages, is highly suggestive of predominant expression of ghrelin in the corpora lutea $(\mathrm{CL})$ of the current cycle. Thus, ghrelin mRNA level reached their highest value when the $C L$ entered into its functional phase and remained lower during $\mathrm{CL}$ formation and regression. This contention was further substantiated by immunohistochemical analyses, which showed intense and specific ghrelin immunoreactivity in the cytoplasm of steroidogenic luteal cells (Caminos et al. 2003). In addition, non-apoptotic cells in regressing $\mathrm{CL}$ from previous cycles and, to a lesser extent, cells from the interstitial gland showed detectable ghrelin immunostaining (Caminos et al. 2003). The profile of ghrelin expression in the $\mathrm{CL}$ was roughly coincidental with its peak in functional activity and paralleled the pattern of progesterone secretion (Duggal et al. 2002, Caminos et al. 2003), which is suggestive of a potential functional role of ghrelin in the regulation of luteal development and/or function in the rat. Nevertheless, whether ghrelin is actually involved in steroidogenesis, angiogenesis, tissue remodeling, and growth of the $\mathrm{CL}$ remains to be established. Overall, these data provide evidence that during the estrous cycle the expression of the gene encoding ghrelin undergoes dynamic changes that result in predominant expression of the peptide in the CL.

In keeping with the functional and morphological data indicative of a predominant expression of ghrelin in the $\mathrm{CL}$ within the cyclic ovary, blockade of the preovulatory surge of gonadotropins and subsequent ovulation by means of administration of a potent gonadotropinreleasing hormone $(\mathrm{GnRH})$ antagonist significantly disturbed the cyclic profile of ovarian ghrelin mRNA 
expression (Nekola \& Coy 1985, Caminos et al. 2003). Indeed, ghrelin mRNA levels in ovaries from rats treated with a single dose of GnRH antagonist persistently remained at values similar to those in the proestrous stage and were significantly lower than those in paired diestrous d 1 and diestrous d 2 cyclic ovaries (Caminos et al. 2003). It is likely that prevention of ovulation which, in turn, blocks formation of the new $\mathrm{CL}$, accounted for the decrease in ghrelin mRNA expression in ovaries from GnRH antagonist-treated rats (Nekola \& Coy 1985, Caminos et al. 2003). Additionally, the reduction of circulating $\mathrm{LH}$ levels after $\mathrm{GnRH}$ antagonist treatment may cause the decrease in ovarian ghrelin mRNA levels. In this sense, we have recently provided evidence for a direct stimulatory role of LH/CG in the control of testicular ghrelin gene expression in interstitial Leydig cells, i.e. the major steroidogenic cell type of the testis. Whether an analogous phenomenon also operates in the ovary awaits further investigation.

In addition, ovarian ghrelin gene expression is markedly influenced by pregnancy. Expression levels of the messenger encoding ghrelin were higher in early pregnancy, and a significant decrease was detected during the later part of gestation (Caminos et al. 2003). In the rat, extension of the luteal function, which, in turn, acts to maintain pregnancy during the first week of gestation, is modulated by $\mathrm{LH}$ and prolactin (PRL; Freeman et al. 2000). However, gestation is maintained during the latter half of pregnancy in the rat by placental production of lactogen and androgens, and by estrogen and progesterone produced by CL (Ben Zimra et al. 2002). Most studies on the biochemistry and structure of the $C L$ suggest that during late pregnancy the $C L$ of the rat is at the very early stages of structural regression, with no changes at the morphological level, but with changes at the molecular level (functional regression). Overall, these data suggest that ghrelin is maximally expressed in functional CL from both current cycle and gestation, with declining expression levels along functional regression of CL. Nevertheless, detailed analyses of the pattern of ghrelin immunoreactivity in rat ovary throughout pregnancy are needed to fully substantiate this hypothesis. In addition, a recent report showed a specific ghrelin inmunostaining in the labyrinth trophoblast cells of rat placenta at term (21 days p.c) whith no positive signal in other placental cell types (Gualillo et al. 2001). A time-course study of ghrelin mRNA levels in rat placenta during pregnancy performed by semiquantitative RT-PCR demonstrated a characteristic profile of expression being practically undetectable during early pregnancy, with a sharp peak at day 16 and still a quite degree of expression at term. Thus, it can be postulated that $\mathrm{LH}$ (and PRL) regulate the expression of ghrelin in the ovary during early pregnancy, whereas placental lactogen could play a pivotal role in the regulation of placental ghrelin mRNA expression during the latter half of pregnancy.

\section{Human data}

The presence and cellular location of ghrelin and its functional receptor, namely the type $1 \mathrm{a}$ GHS-R in the cyclic human ovary, have been reported using immunohistochemistry with polyclonal antibodies (Gaytan et al. 2003). Strong ghrelin immunostaining was demonstrated in ovarian hilus interstitial cells. By contrast, ghrelin signal was not detected in ovarian follicles at any developmental stage, nor was it present in newly formed $\mathrm{CL}$ in very early development. However, specific ghrelin immunoreactivity was clearly observed in young and mature $\mathrm{CL}$, whereas expression of the peptide disappeared in regressing luteal tissue. Ovarian expression of GHS-R1a protein showed a wider pattern of tissue distribution, with detectable specific signal in oocytes as well as somatic follicular cells, luteal cells from young, mature, old, and regressing $\mathrm{CL}$, and interstitial hilus cells. Of particular note, follicular GHS-R1a peptide expression paralleled follicle development with stronger immunostaining in granulosa and theca layers of healthy antral follicles. The presence of both components (ligand and receptor) of the ghrelin signaling system within the human ovary opens up the possibility of a potential regulatory role of this novel molecule in ovarian function under physiological and pathophysiological conditions. To this end, expression of GHS-R1a was analyzed by immunohistochemistry in a panel of normal, metaplastic, and neoplastic tissues (Gaytan et al. 2005). Uniform GHS-R1a immunostaining was detected throughout the ovarian surface epithelium. Likewise, ciliated cells within the fallopian tube epithelium showed strong GHS-R1a expression. By contrast, other celomic derivatives, such as endometrium and endocervix, were negative for GHS-R1a immunoreactivity. In keeping with data from normal tissues, inclusion cysts from the surface epithelium expressed GHS-R1a. Similarly, benign serous tumors resembling fallopian tube epithelium were also positive, whereas serous cystadenocarcinomas showed GHS-R1a expression only in highly differentiated specimens. By contrast, other neoplasms, such as mucinous cystadenomas and cystadenocarcinomas, endometrioid tumors, clear cell carcinomas, and Brenner tumors, did not express GHS-R1a. This pattern of expression is in agreement with the proposed role for ghrelin in the autocrine/paracrine control of cell proliferation and cancer. Proliferative actions of ghrelin (or its synthetic analogs, the GHSs) are observed in prostate (PC-3) and thyroid (anaplastic carcinoma; ARO) cancer cell lines as well as the cardiomyocyte H9c2 cell line and cultured adrenocortical cells (Cassoni et al. 2000, Pettersson et al. 2002, Andreis et al. 2003, Jeffery et al. 2003). Conversely, anti-proliferative effects of ghrelin/GHSs are observed in several thyroid (papillary carcinoma; NPA, follicular carcinoma; WRO), lung (CALU-1), and breast (MCF7, T47D, MDA-MB231) cancer cell lines (Cassoni et al. 2000, 2001, Ghe et al. 
2002) as well as in immature Leydig cells of the testis (Barreiro et al. 2004). It remains to be proved whether the ovarian surface epithelium and related tumors are potential targets for systemic or locally produced ghrelin because they express the functional type 1a GHS-R. Considering the relevant role of the ovarian surface epithelium in key physiological events (such as ovulation) and neoplastic transformation of the ovary, the potential actions of ghrelin in those phenomena merit further investigation.

\section{Systemic actions of ghrelin upon the reproductive axis}

The reproductive facets of ghrelin are not apparently restricted to its expression and/or direct actions at the ovary and testis, and extragonadal actions of ghrelin within the reproductive axis have also been documented. However, so far the available data in this area are still fragmentary. In principle, considering the proposed role of ghrelin as peripheral signal for energy insufficiency (Zigman \& Elmquist 2003), and the proven reproductive effects of other known regulators of energy balance, such as leptin, it appears feasible that circulating ghrelin might contribute to the functional control of the reproductive axis and its integration with energy balance.

\section{Rodent data}

Given their pivotal role in the hormonal control of reproduction (Tena-Sempere \& Huhtaniemi 2003), the effects of ghrelin upon gonadotropin and PRL secretion have been explored in a limited number of models and animals species. Initial data evidenced that central administration of ghrelin suppressed pulsatile LH secretion in ovariectomized female rats (Furuta et al. 2001). In good agreement, intracerebroventricular administration of ghrelin $(3 \mathrm{nmol} / \mathrm{rat})$ evoked a significant inhibition of $\mathrm{LH}$ secretion in cyclic female rats throughout the estrous cycle (proestrus afternoon, estrus, metestrus), as well as in ovariectomized females (Fernandez-Fernandez et al. 2006). Likewise, GnRH secretion by hypothalamic fragments from ovariectomized females was significantly inhibited by ghrelin (Fernandez-Fernandez et al. 2006). In contrast, ghrelin dose-dependently stimulated basal $\mathrm{LH}$ and $\mathrm{FSH}$ secretion by pituitary tissue in vitro; a phenomenon that was proven dependent on the phase of estrous cycle, as it was neither detected at estrus nor observed after ovariectomy (Fernandez-Fernandez et al. 2006). Conversely, GnRH-stimulated $\mathrm{LH}$ secretion in vitro was persistently inhibited by ghrelin regardless of the stage of the cycle, whereas stimulated FSH secretion was only inhibited by ghrelin at estrus. In addition, cyclic fluctuations in mRNA levels of GHS-R 1a, i.e. the functional ghrelin receptor, were observed in the pituitary, with low values at estrus and metestrus (Fernandez-Fernandez et al. 2006). In summary, these data illustrate a complex mode of action of ghrelin upon the gonadotropic axis, with predominant inhibitory effects at central (hypothalamic) levels and upon $\mathrm{GnRH}$-induced gonadotropin secretion, but direct stimulatory actions on basal $\mathrm{LH}$ and $\mathrm{FSH}$ secretion. In this regard, our findings indicate that daily injection of ghrelin or UAG throughout puberty in male rats similarly decreased LH concentrations (Martini et al. 2006). Moreover, acute injection of ghrelin induced a transient reduction levels and partially delayed balanopreputial separation (Fernandez-Fernandez et al. 2005, Martini et al. 2006; Fig. 1). Likewise, chronic infusion of ghrelin
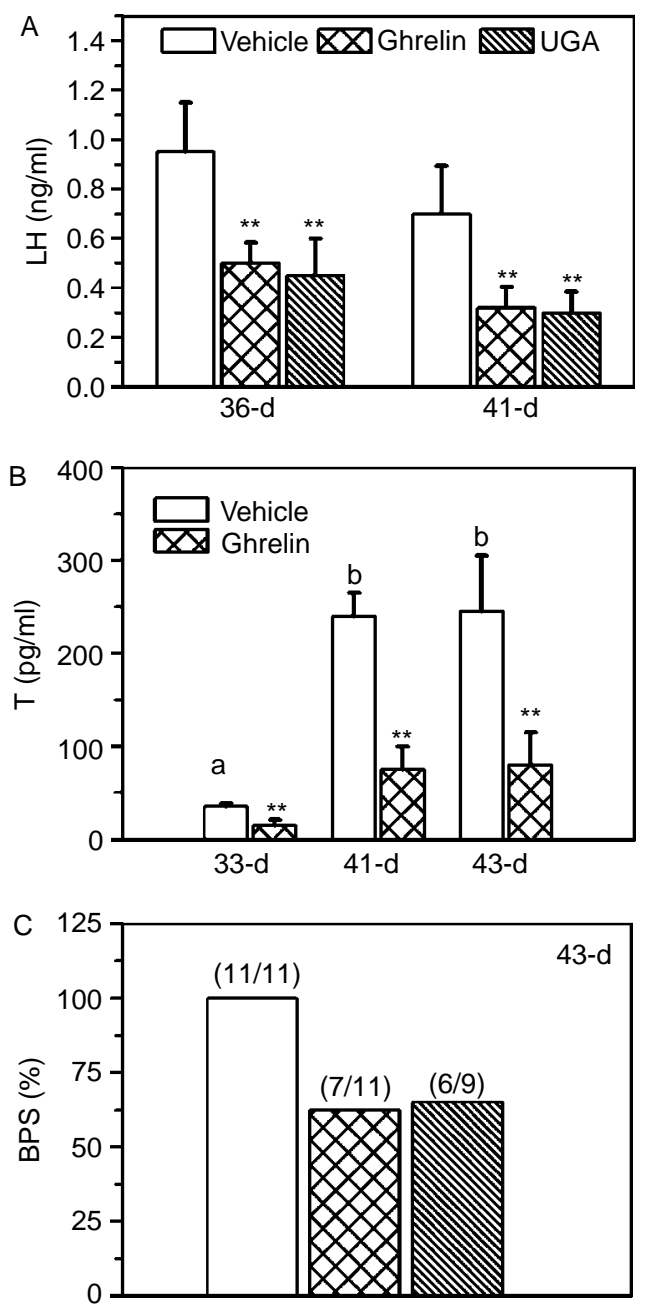

Figure 1 Ghrelin and UAG - puberty in males. Repeated administration of ghrelin or UAG to pubertal male rats partially alters normal puberty onset. Repeated injection of acylghrelin or UAG $(1 \mathrm{nmol} / 12 \mathrm{~h})$ between postnatal days 34-43 significantly decreased serum $\mathrm{LH}$ (A) and testosterone (B) levels and partially disrupted normal timing of puberty onset (C), as estimated by the presence of balanopreputial separation (BPS) at $d-43$. Values are given as mean \pm s.E.M. For vehicle treated animals, groups with different superscript letters were statistically different $(P<0.05)$. ${ }^{* *} P<0.01$ vs corresponding vehicle treated animals. Adapted from Fernandez-Fernandez et al. (2005) and Martini et al. (2006). 
or UAG to adult males resulted in significant decreases in circulating $\mathrm{LH}$ and FSH levels in freely moving males, an effect that was fully mimicked by administration of UAG (Martini et al. 2006; Fig. 2). Yet in contrast to ghrelin, UAG failed to modify $\mathrm{GH}$ secretion. Finally, injection of ghrelin moderately, but significantly, reduced the duration of $\mathrm{LH}$ secretory responses to the potent gonadotropin secretagogue kisspeptin-10, whereas ghrelin infusion in a model of chronic elevation of serum gonadotropin levels (the transgenic growth retarded male rat) evoked a significant reduction of $\mathrm{LH}$ concentrations (Martini et al. 2006). Altogether these data further substantiate the inhibitory effect of ghrelin on basal and stimulated LH secretion in a wide array of experimental conditions. Moreover, these data show the ability of UAG, originally considered an inert form of the molecule, to mimic the actions of acylated ghrelin on LH release. These observations reinforce the contention that ghrelin, as putative signal for energy insufficiency, may operate as negative modifier of male puberty and LH secretion, an effect that might be, at least partially, conducted through a GH secretagogue receptor type 1aindependent mechanism. The mechanisms for such an effect might involve the inhibition of $\mathrm{LH}$ secretion at the hypothalamic-pituitary unit and/or direct inhibitory effects on testicular testosterone secretion.

Besides its neuroendocrine effects upon gonadotropic and lactotropic axes in the rat, ghrelin expression has been also detected in rat placenta (Gualillo et al. 2001). In
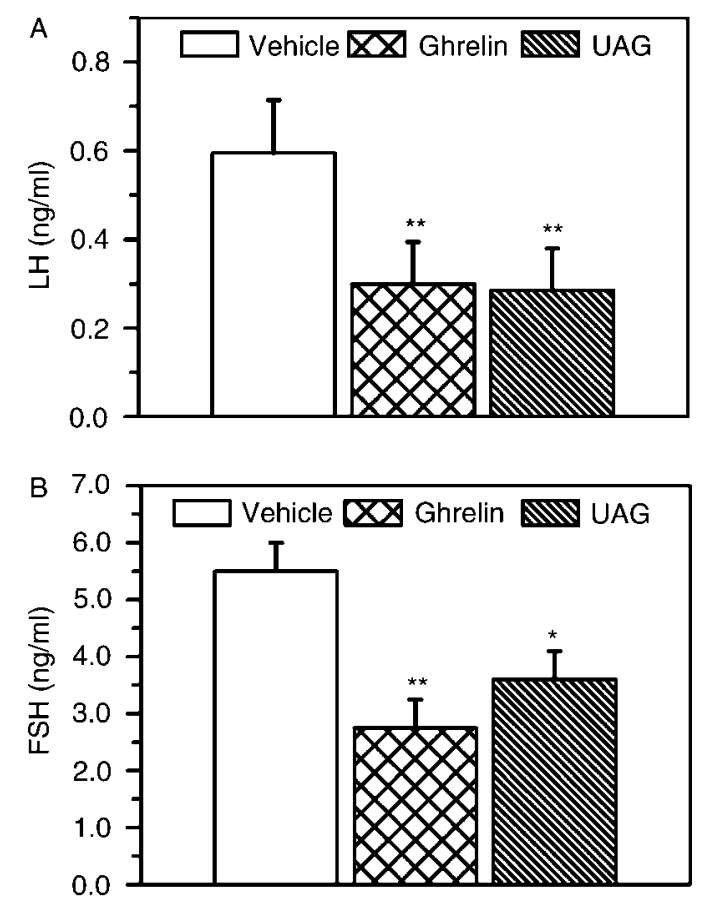

Figure 2 Ghrelin and UAG-Serum gonadotropin levels in males. Chronic i.v. administration of ghrelin or UAG $(1 \mathrm{nmol} / 12 \mathrm{~h})$ for seven days in adult male rats significantly decreased serum $\mathrm{LH}(\mathrm{A})$ and $\mathrm{FSH}(\mathrm{B})$ levels. Values are given as mean \pm S.E.M. ${ }^{*} P<0.05$ and ${ }^{* *} P<0.01$ vs corresponding vehicle treated animals. Adapted from Martini et al. (2006). addition, ghrelin levels in uterine fluid have been proven to dramatically increase during fasting in mice, and ghrelin has been recently reported to inhibit the development of mouse preimplantation embryos in vitro (Kawamura et al. 2003). In good agreement, we have recently observed that chronic ghrelin treatment during the first half of pregnancy in the rat induced a significant reduction in the litter size (Fernandez-Fernandez et al. 2005). Overall, it is tempting to propose that ghrelin may operate as key signal for energy insufficiency during early stages of gestation, acting as inhibitory factor in early embryo development in order to avoid the excessive metabolic drain linked to pregnancy and lactation in situations of malnutrition (Kawamura et al. 2003).

\section{Human data}

The potential effects of ghrelin in the control of the reproductive system in humans (and primates) have been very scarcely evaluated. Only recently, the original observations of a inhibitory role of ghrelin in the control of LH secretion in rodents (Furuta et al. 2001, Fernandez-Fernandez et al. 2004) have been corroborated by experiments conducted in ovariectomized rhesus monkeys, after detailed analyses of the pulsatile pattern of LH release after infusion of ghrelin (Vulliemoz et al. 2004). In humans, however, although stimulatory responses in terms of PRL secretion have been repeatedly reported after acute administration of the peptide, specific effects of ghrelin upon LH secretion have not been demonstrated (van der Lely et al. 2004). Yet, it remains possible that more detailed analyses, involving precise assessment of $\mathrm{LH}$ pulsatility after ghrelin administration, might unravel a subtle regulatory role of ghrelin in the control of gonadotropin secretion in humans. Of note, androgens have been recently shown as independent modulators of ghrelin levels in male and female humans (Pagotto et al. 2002, 2003, Gambineri et al. 2003). The policystic ovary syndrome (PCOS), is a condition characterized by hyperandrogenism, chronic anovulation, insulin resistance, and frequently associated with obesity (Micic et al. 2003). Pagotto et al. (2002) have reported that obese women with PCOS have even lower ghrelin levels than expected on the basis of their obese phenotype and a strong negative correlation between ghrelin and circulating androgen parameters, particularly androstendione, was also described (Pagotto et al. 2002). Moreover, a long-term treatment with the anti-androgen agent, flutamide, in PCOS women significantly increased ghrelin levels (Gambineri et al. 2003). The same group also found that circulating ghrelin levels were significantly decreased in obese hipogonadal men compared to their overweight matched controls and a positive correlation between ghrelin and total and free testosterone concentrations was described in this study (Pagotto et al. 2003). Likewise, a long-term replacement testosterone therapy 
in hypogonadal patients restored circulating ghrelin levels to those found in control normal subjects. Thus, it appears feasible that ghrelin and sex steroids reciprocally interact (ghrelin modulates androgen secretion - rat data-; androgen modulates ghrelin secretion-human data-) for the integrated control of reproduction and energy balance.

As was the case in the rat, ghrelin expression has been also detected in human placenta (Gualillo et al. 2001), and ghrelin has been demonstrated in human fetal circulation (Cortelazzi et al. 2003). However, the role, if any, of placental and fetal ghrelin in the regulation of gestational growth and metabolism remains to be fully elucidated. In addition, expression of ghrelin has been observed in non-pregnant and decidualized endometrium, and ghrelin has been involved as paracrine/ autocrine regulator of decidualization of human endometrial stromal cells and, tentatively, in the cross-talk between endometrium and embryo during implantation (Tanaka et al. 2003). Whether ghrelin, as suggested for laboratory rodents, may function as putative modifier of human gestation in situations of energy deficit remains to be elucidated.

\section{Unsolved questions: concluding remarks}

Our knowledge on the potential actions of ghrelin on the mammalian gonads has enlarged considerably in the last few years, yet there are still many open questions concerning the physiological contribution of ghrelin in the control of gonadal function. For instance, whereas potential inhibitory effects of ghrelin upon testicular steroid secretion have been evidenced using in vitro models (Fig. 3; Tena-Sempere et al. 2002), elucidation of the impact of persistent hyperghrelinemia upon circulating levels of androgens and estrogens in vivo awaits to be
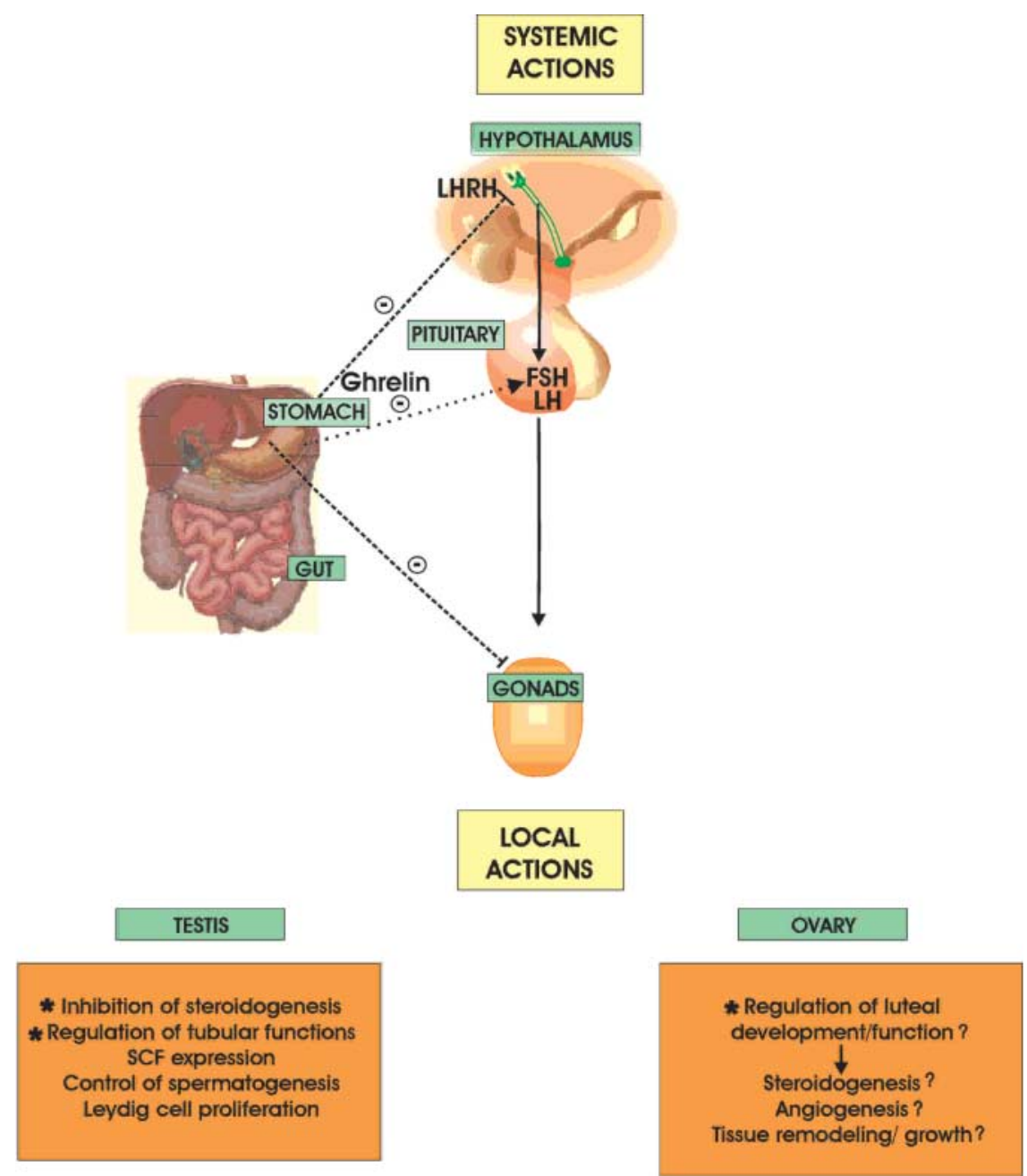

Figure 3 Schematic model for the postulated reproductive actions of ghrelin. In the upper panel, the potential SYSTEMIC actions of gut-derived circulating ghrelin at different levels of the hypothalamic-pituitary-axis are depicted. In addition, LOCAL expression of ghrelin is detected in the human and rat gonads. In the lower panel the proposed direct actions of ghrelin in the testis and ovary are summarized. A question mark (?) indicates that the effect was not studied. 
elucidated. Likewise, ovarian and testicular actions of ghrelin other than the control of the steroidogenic function are anticipated (Barreiro et al. 2004); yet, they remain to be studied in detail (Fig. 3). In this sense, it will be interesting to test whether unacylated ghrelin, conventionally regarded as an inert form of the molecule but recently proven as biologically active in specific cellular contexts (van der Lely et al. 2004) might mimic and/or modulate the reported effect of acylated ghrelin upon cell proliferation and gene expression in ovary and testis. Finally, an interesting observation is that several testicular tumors were recently proven to express ghrelin and/or GHS-R1a (Gaytan et al. 2004). It is yet to be determined, however, whether ghrelin might conduct specific regulatory actions upon testicular tumor cell proliferation. To be noted, expression of ghrelin has been previously demonstrated in several endocrine tumors, such as pituitary-, stomach- and pancreas-derived tumors, i.e. tissues that normally express ghrelin (van der Lely et al. 2004), and proliferative or anti-proliferative effects of ghrelin have been variably reported depending on the tumor cell line and dose of ghrelin used (Jeffery et al. 2003).

Although testing of the effects of its acute administration has suggested a possible role of ghrelin in the control of the gonadotropic axis (Fig. 3), the impact of persistently elevated ghrelin levels upon sensitive reproductive parameters has not been addressed so far. The working hypothesis is that, given its role as a signal for energy insufficiency, chronic hyperghrelinemia (as expected in situations of negative energy balance) might be detrimental for reproductive function. Indeed, studies on the effects of repeated administration of ghrelin upon several reproductive parameters of the rat are currently in progress in our laboratory. Likewise, we are presently analyzing the primary sites and mechanisms of action whereby ghrelin regulates $\mathrm{LH}$ and $\mathrm{PRL}$ secretion. We anticipate that elucidation of the sites and mechanisms of action of ghrelin, together with the complete characterization of its effects, will help to define the physiological roles of ghrelin in the control of the reproductive system, and its contribution for the integration of energy balance and fertility. Noteworthy recent reports (Smith, unpublished observations) have indicated that marked impairment in gonadal function and fertility in the ob/ob mice can be reversed when crossed with the ghrelin $\mathrm{KO}$ mice, imply a major role of leptin and ghrelin in the control of gonadal function. Future studies, assessing the analysis of the putative reproductive effects of octanoylated- as well as unacylated-ghrelin, not only upon pituitary hormone secretion, but also in terms of sexual development and gestation are eagerly awaited.

\section{Acknowledgements}

This work was supported by grants from the MEC (BFU 2006), Xunta de Galicia and EU (LSHM-CT-2003-503041). MG, ML, FC and CD are members of the CIBER on Obesity and Nutrition
(Instituto de Salud Carlos III). The authors declare that there is no conflict of interest that would prejudice the impartiality of this scientific work.

\section{References}

Andreis PG, Malendowicz LK, Trejter M, Neri G, Spinazzi R, Rossi GP \& Nussdorfer GG 2003 Ghrelin and growth hormone secretagogue receptor are expressed in the rat adrenal cortex: evidence that ghrelin stimulates the growth, but not the secretory activity of adrenal cells. FEBS Letters 536 173-179.

Barreiro ML, Gaytan F, Caminos JE, Pinilla L, Casanueva FF, Aguilar E, Dieguez C \& Tena-Sempere M 2002 Cellular location and hormonal regulation of ghrelin expression in rat testis. Biology of Reproduction 67 1768-1776.

Barreiro ML, Suominen JS, Gaytan F, Pinilla L, Chopin LK, Casanueva FF, Dieguez C, Aguilar E, Toppari J \& Tena-Sempere M 2003 Developmental, stage-specific, and hormonally regulated expression of growth hormone secretagogue receptor messenger RNA in rat testis. Biology of Reproduction 68 1631-1640.

Barreiro ML, Gaytan F, Castellano JM, Suominen JS, Roa J, Gaytan M, Aguilar E, Dieguez C, Toppari J \& Tena-Sempere M 2004 Ghrelin inhibits the proliferative activity of immature Leydig cells in vivo and regulates stem cell factor messenger ribonucleic acid expression in rat testis. Endocrinology 145 4825-4834.

Bedendi I, Alloatti G, Marcantoni A, Malan D, Catapano F, Ghe C, Deghenghi R, Ghigo E \& Muccioli G 2003 Cardiac effects of ghrelin and its endogenous derivatives des-octanoyl ghrelin and des-Gln14ghrelin. European Journal of Pharmacology 476 87-95.

Ben Zimra M, Koler M, Melamed-Book N, Arensburg J, Payne AH \& Orly J 2002 Uterine and placental expression of steroidogenic genes during rodent pregnancy. Molecular and Cellular Endocrinology 187 223-231.

Broglio F, Benso A, Gottero C, Prodam F, Gauna C, Filtri L, Arvat E, van der Lely AJ, Deghenghi R \& Ghigo E 2003 Non-acylated ghrelin does not possess the pituitaric and pancreatic endocrine activity of acylated ghrelin in humans. Journal of Endocrinological Investication 26 192-196.

Caminos JE, Tena-Sempere M, Gaytan F, Sanchez-Criado JE, Barreiro ML, Nogueiras R, Casanueva FF, Aguilar E \& Dieguez C 2003 Expression of ghrelin in the cyclic and pregnant rat ovary. Endocrinology 144 1594-1602.

Cassoni P, Papotti M, Catapano F, Ghe C, Deghenghi R, Ghigo E \& Muccioli G 2000 Specific binding sites for synthetic growth hormone secretagogues in non-tumoral and neoplastic human thyroid tissue. Journal of Endocrinology 165 139-146.

Cassoni P, Papotti M, Ghe C, Catapano F, Sapino A, Graziani A, Deghenghi R, Reissmann T, Ghigo E \& Muccioli G 2001 Identification, characterization, and biological activity of specific receptors for natural (ghrelin) and synthetic growth hormone secretagogues and analogs in human breast carcinomas and cell lines. Journal of Clinical Endocrinology and Metabolism 86 1738-1745.

Cortelazzi D, Cappiello V, Morpurgo PS, Ronzoni S, Nobile De Santis MS, Cetin I, Beck-Peccoz P \& Spada A 2003 Circulating levels of ghrelin in human fetuses. European Journal of Endocrinology 149 111-116.

Dornonville dl C, Lindqvist A, Egecioglu E, Tung YC, Surve V, Ohlsson C, Jansson JO, Erlanson-Albertsson C, Dickson SL \& Hakanson R 2005 Ghrelin treatment reverses the reduction in weight gain and body fat in gastrectomised mice. Gut 54 907-913.

Duggal PS, Weitsman SR, Magoffin DA \& Norman RJ 2002 Expression of the long (OB-RB) and short (OB-RA) forms of the leptin receptor throughout the oestrous cycle in the mature rat ovary. Reproduction 123 899-905. 
Fernandez-Fernandez R, Tena-Sempere M, Aguilar E \& Pinilla L 2004 Ghrelin effects on gonadotropin secretion in male and female rats. Neuroscience Letters 362 103-107.

Fernandez-Fernandez R, Navarro VM, Barreiro ML, Vigo EM, Tovar S, Sirotkin AV, Casanueva FF, Aguilar E, Dieguez C, Pinilla L \& TenaSempere M 2005 Effects of chronic hyperghrelinemia on puberty onset and pregnancy outcome in the rat. Endocrinology 146 3018-3025.

Fernandez-Fernandez R, Tena-Sempere M, Navarro VM, Barreiro ML, Castellano JM, Aguilar E \& Pinilla L 2006 Effects of Ghrelin upon Gonadotropin-Releasing Hormone and Gonadotropin Secretion in Adult Female Rats: in vivo and in vitro Studies. Neuroendocrinology 82 245-255.

Freeman ME, Kanyicska B, Lerant A \& Nagy G 2000 Prolactin: structure, function, and regulation of secretion. Physiological Reviews 80 1523-1631.

Furuta M, Funabashi T \& Kimura F 2001 Intracerebroventricular administration of ghrelin rapidly suppresses pulsatile luteinizing hormone secretion in ovariectomized rats. Biochemical and Biophysical Research Communications 288 780-785.

Gambineri A, Pagotto U, Tschop M, Vicennati V, Manicardi E, Carcello A, Cacciari M, De lasio R \& Pasquali R 2003 Antiandrogen treatment increases circulating ghrelin levels in obese women with polycystic ovary syndrome. Journal of Endocrinological Investigation 26 629-634.

Gaytan F, Barreiro ML, Chopin LK, Herington AC, Morales C, Pinilla L, Casanueva FF, Aguilar E, Dieguez C \& Tena-Sempere M 2003 Immunolocalization of ghrelin and its functional receptor, the type 1a growth hormone secretagogue receptor, in the cyclic human ovary. Journal of Clinical Endocrinology and Metabolism 88 879-887.

Gaytan F, Barreiro ML, Caminos JE, Chopin LK, Herington AC, Morales C, Pinilla L, Paniagua R, Nistal M, Casanueva FF, Aguilar E, Dieguez C \& Tena-Sempere M 2004 Expression of ghrelin and its functional receptor, the type 1a growth hormone secretagogue receptor, in normal human testis and testicular tumors. Journal of Clinical Endocrinology and Metabolism 89 400-409.

Gaytan F, Morales C, Barreiro ML, Jeffery P, Chopin LK, Herington AC, Casanueva FF, Aguilar E, Dieguez C \& Tena-Sempere M 2005 Expression of growth hormone secretagogue receptor type $1 \mathrm{a}$, the functional ghrelin receptor, in human ovarian surface epithelium, mullerian duct derivatives, and ovarian tumors. Journal of Clinical Endocrinology and Metabolism 90 1798-1804.

Ghe C, Cassoni P, Catapano F, Marrocco T, Deghenghi R, Ghigo E, Muccioli G \& Papotti M 2002 The antiproliferative effect of synthetic peptidyl GH secretagogues in human CALU-1 lung carcinoma cells. Endocrinology 143 484-491.

Gnanapavan S, Kola B, Bustin SA, Morris DG, McGee P, Fairclough P, Bhattacharya S, Carpenter R, Grossman AB \& Korbonits M 2002 The tissue distribution of the mRNA of ghrelin and subtypes of its receptor, GHS-R, in humans. Journal of Clinical Endocrinology and Metabolism 872988.

Gualillo O, Caminos J, Blanco M, Garcia-Caballero T, Kojima M, Kangawa K, Dieguez C \& Casanueva F 2001 Ghrelin, a novel placental-derived hormone. Endocrinology 142 788-794.

Hakovirta H, Yan W, Kaleva M, Zhang F, Vanttinen K, Morris PL, Soder M, Parvinen M \& Toppari J 1999 Function of stem cell factor as a survival factor of spermatogonia and localization of messenger ribonucleic acid in the rat seminiferous epithelium. Endocrinology 140 1492-1498.

Hosoda H, Kojima M, Matsuo H \& Kangawa K 2000a Ghrelin and desacyl ghrelin: two major forms of rat ghrelin peptide in gastrointestinal tissue. Biochemical and Biophysical Research Communications 279 909-913.

Hosoda H, Kojima M, Matsuo H \& Kangawa K 2000 b Purification and characterization of rat des-Gln14-Ghrelin, a second endogenous ligand for the growth hormone secretagogue receptor. Journal of Biological Chemistry 275 21995-22000.
Jeffery PL, Herington AC \& Chopin LK 2003 The potential autocrine/paracrine roles of ghrelin and its receptor in hormonedependent cancer. Cytokine \& Growth Factor Reviews 14 113-122.

Kawamura K, Sato N, Fukuda J, Kodama H, Kumagai J, Tanikawa H, Nakamura A, Honda Y, Sato T \& Tanaka T 2003 Ghrelin inhibits the development of mouse preimplantation embryos in vitro. Endocrinology $1442623-2633$.

Kojima M, Hosoda H, Date Y, Nakazato M, Matsuo H \& Kangawa K 1999 Ghrelin is a growth-hormone-releasing acylated peptide from stomach. Nature 402 656-660.

Martini AC, Fernandez-Fernandez R, Tovar S, Navarro VM, Vigo E, Vazquez MJ, Davies JS, Thompson NM, Aguilar E, Pinilla L, Wells T, Dieguez C \& Tena-Sempere M 2006 Comparative analysis of the effects of ghrelin and unacylated ghrelin on luteinizing hormone secretion in male rats. Endocrinology 147 2374-2382.

Micic D, Sumarac-Dumanovic M, Macut D, Kendereski A, Zoric S, Popovic V, Cvijovic G, Dieguez C \& Casanueva FF 2003 Growthhormone response to combined stimulation with $\mathrm{GHRH}$ plus GH-releasing peptide- 6 in obese patients with polycystic ovary syndrome before and after short-term fasting. Journal of Endocrinological Investigation 26 333-340.

Nanzer AM, Khalaf S, Mozid AM, Fowkes RC, Patel MV, Burrin JM, Grossman AB \& Korbonits M 2004 Ghrelin exerts a proliferative effect on a rat pituitary somatotroph cell line via the mitogenactivated protein kinase pathway. European Journal of Endocrinology 151 233-240.

Nekola MV \& Coy DH 1985 Direct and indirect inhibition of ovulation in rats by an antagonist of luteinizing hormone-releasing hormone. Endocrinology 116 756-760.

Pagotto U, Gambineri A, Vicennati V, Heiman ML, Tschop M \& Pasquali R 2002 Plasma ghrelin, obesity, and the polycystic ovary syndrome: correlation with insulin resistance and androgen levels. Journal of Clinical Endocrinology and Metabolism 87 5625-5629.

Pagotto U, Gambineri A, Pelusi C, Genghini S, Cacciari M, Otto B, Castaneda T, Tschop M \& Pasquali R 2003 Testosterone replacement therapy restores normal ghrelin in hypogonadal men. Journal of Clinical Endocrinology and Metabolism 88 4139-4143.

Papotti M, Ghe C, Cassoni P, Catapano F, Deghenghi R, Ghigo E \& Muccioli G 2000 Growth hormone secretagogue binding sites in peripheral human tissues. Journal of Clinical Endocrinology and Metabolism 85 3803-3807.

Pettersson I, Muccioli G, Granata R, Deghenghi R, Ghigo E, Ohlsson C \& Isgaard J 2002 Natural (ghrelin) and synthetic (hexarelin) GH secretagogues stimulate H9c2 cardiomyocyte cell proliferation. Journal of Endocrinology 175 201-209.

Tanaka M, Hayashida Y, Nakao N, Nakai N \& Nakashima K 2001 Testis-specific and developmentally induced expression of a ghrelin gene-derived transcript that encodes a novel polypeptide in the mouse. Biochimica et Biophysica Acta 1522 62-65.

Tanaka K, Minoura H, Isobe T, Yonaha H, Kawato H, Wang DF, Yoshida T, Kojima M, Kangawa K \& Toyoda N 2003 Ghrelin is involved in the decidualization of human endometrial stromal cells. Journal of Clinical Endocrinology and Metabolism 88 2335-2340.

Tena-Sempere M \& Barreiro ML 2002 Leptin in male reproduction: the testis paradigm. Molecular and Cellular Endocrinology 188 9-13.

Tena-Sempere M \& Huhtaniemi I 2003 Gonadotropins and gonadotropin receptors, Reproductive Medicine, Molecular, Cellular and Genetic Fundamentals, New York, NY: Parthenon Publishing, pp. 225-244.

Tena-Sempere M, Barreiro ML, Gonzalez LC, Gaytan F, Zhang FP, Caminos JE, Pinilla L, Casanueva FF, Dieguez C \& Aguilar E 2002 Novel expression and functional role of ghrelin in rat testis. Endocrinology 143 717-725.

Thompson NM, Gill DA, Davies R, Loveridge N, Houston PA, Robinson IC \& Wells T 2004 Ghrelin and des-octanoyl ghrelin promote adipogenesis directly in vivo by a mechanism independent of the type 1 a growth hormone secretagogue receptor. Endocrinology 145 234-242. 
Tomasetto C, Karam SM, Ribieras S, Masson R, Lefebvre O, Staub A, Alexander G, Chenard MP \& Rio MC 2000 Identification and characterization of a novel gastric peptide hormone: the motilinrelated peptide. Gastroenterology 119 395-405.

van der Lely AJ, Tschop M, Heiman ML \& Ghigo E 2004 Biological, physiological, pathophysiological, and pharmacological aspects of ghrelin. Endocrine Reviews 25 426-457.

Vulliemoz NR, Xiao E, Xia-Zhang L, Germond M, Rivier J \& Ferin M 2004 Decrease in luteinizing hormone pulse frequency during a fivehour peripheral ghrelin infusion in the ovariectomized rhesus monkey. Journal of Clinical Endocrinology and Metabolism 89 5718-5723.

Yan W, Kero J, Huhtaniemi I \& Toppari J 2000a Stem cell factor functions as a survival factor for mature Leydig cells and a growth factor for precursor Leydig cells after ethylene dimethane sulfonate treatment: implication of a role of the stem cell factor/c-Kit system in Leydig cell development. Developmental Biology 227 169-182.

Yan W, Suominen J \& Toppari J 2000b Stem cell factor protects germ cells from apoptosis in vitro. Journal of Cell Science $\mathbf{1 1 3}$ 161-168.

Zigman JM \& Elmquist JK 2003 Minireview: from anorexia to obesity the yin and yang of body weight control. Endocrinology 144 3749-3756.

Received 4 October 2006

First decision 14 November 2006

Accepted 11 December 2006 